\title{
Myriam Vaucher, Dominique Bourdin, Marcel Durrer, Olivier Revaz (Ed.), Foi de cannibale ! La dévoration, entre religion et psychanalyse
} Genève, Labor et Fides, coll. « Psychologie et spiritualité », 2012, 408 p.

\section{Daniel Vidal}

\section{OpenEdition \\ Journals}

Édition électronique

URL : http://journals.openedition.org/assr/25656

DOI : $10.4000 /$ assr.25656

ISSN : $1777-5825$

Éditeur

Éditions de l'EHESS

Édition imprimée

Date de publication : 30 décembre 2013

Pagination : 301

ISSN : 0335-5985

Référence électronique

Daniel Vidal, « Myriam Vaucher, Dominique Bourdin, Marcel Durrer, Olivier Revaz (Ed.), Foi de cannibale! La dévoration, entre religion et psychanalyse », Archives de sciences sociales des religions [En ligne], 164 | 2013, mis en ligne le 14 mars 2014, consulté le 21 septembre 2020. URL : http:// journals.openedition.org/assr/25656; DOI : https://doi.org/10.4000/assr.25656

Ce document a été généré automatiquement le 21 septembre 2020.

(c) Archives de sciences sociales des religions 
Myriam Vaucher, Dominique Bourdin, Marcel Durrer, Olivier Revaz (Ed.), Foi de cannibale! La dévoration, entre religion et psychanalyse

Genève, Labor et Fides, coll. « Psychologie et spiritualité », 2012, 408 p.

Daniel Vidal

\section{RÉFÉRENCE}

Myriam Vaucher, Dominique Bourdin, Marcel Durrer, Olivier Revaz (Ed.), Foi de cannibale! La dévoration, entre religion et psychanalyse, Genève, Labor et Fides, coll. «Psychologie et spiritualité », 2012, 408 p. 
1 «La rencontre de l'homme avec le monde qui s'opère dans la bouche grande ouverte qui broie, déchire et mâche est un des sujets les plus anciens et les plus marquants de la pensée humaine. L'homme déguste le monde, sent le goût $\mathrm{du}$ monde, l'introduit dans le corps, en fait une partie de soi ». Commentant l'œuvre de Rabelais, Bakhtine illustre avec bonheur, et précision, le thème central de cet ouvrage collectif, où théologiens, anthropologues, psychanalystes et psychologues explorent les fondements et les aventures de la pulsion dévorante. Quelle relation la dévoration entretientelle avec le lien social ? À quel interdit est soumis l'acte cannibale? Et pour quel bénéfice psychique et culturel? La construction de l'humain passe-t-elle nécessairement par cet impératif de

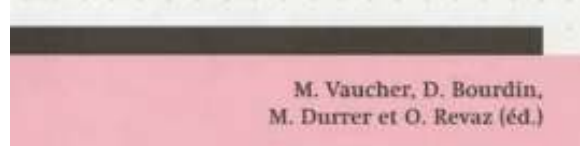

\section{Foi de cannibale!}
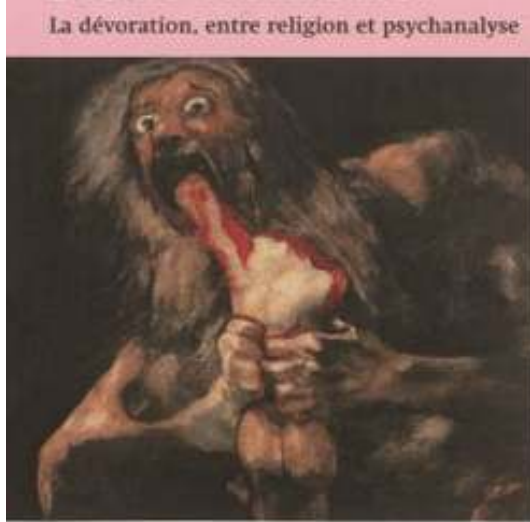

I. Laton ET fots destruction? Mais tout cannibalisme est-il réductible à cette violence improductive? Mondher Kilani pose en initiale la thèse du cannibalisme comme « opérateur symbolique de l'identité et de l'altérité, du dedans et $\mathrm{du}$ dehors, de l'ordre culturel et de l'ordre naturel, de l'humain et du non humain ». Soit les grandes distinctions/oppositions qui structurent l'avènement de l'homme, sujet personnel ou sujet collectif, au cœur de son monde, et la possibilité de son appropriation. Mais le cannibalisme n'est pas immédiatement opérateur symbolique. La dévoration sauvage est proprement, et uniquement, destructrice : rien en elle qui participe de la constitution du sujet. Au contraire, ce qui est dévoré est maintenu en son caractère de simple objet, indifférencié du monde des choses. De même que la prohibition de l'inceste fait obligation d'exogamie, donc de référence à un principe d'altérité, de même la prohibition du cannibalisme "sauvage » permet-elle d'établir entre celui qui dévore et celui qui est dévoré, une relation d'identification et d'absorption des qualités et puissances de celui-ci par celui-là. Ingérer partie du corps de l'étranger est définir en lui à la fois un principe de similitude et d'altérité, et s'appréhender comme extérieur à soi-même: "L'acte d'ingérer l'autre permet de palper l'extériorité en se voyant du dehors ». Freud et Lévi-Strauss sont ainsi régulièrement convoqués par la plupart des intervenants, pour la compréhension des mécanismes pulsionnels au fondement de la subjectivité, et des structurations élémentaires au principe de la vie sociale.

2 Parce qu'il s'oppose à la dévoration bestiale, le cannibalisme ritualisé est un élément fondateur de la régulation sociale. S'il permet d'abord de traiter les désirs pulsionnels les plus archaïques et d'en proposer les équivalents symboliques, il engage le vivant à penser la mort en d'autres termes que de pur abandon. Contre la volonté de Créon, Antigone supplie que les honneurs funèbres soient accordés à son frère, afin de dérober sa dépouille aux bêtes qui la dévoreraient. Muriel Katz-Gilbert analyse cette supplique comme l'impératif d'en finir avec la dévoration "primitive », et la nécessité de lui 
opposer le pendant prescriptif de la ritualité funéraire. Il en va de même de l'interdit de meurtre, corrélé à la prohibition de la dévoration sauvage : « tu ne tueras point » doit s'entendre ainsi, selon Lévinas, «tu feras tout pour que l'autre vive ». Réversibilité de tout appareillage pulsionnel : le cannibalisme, cette «métaphore de la construction de l'humain ", n'est tel qu'au prix d'un retournement/ refoulement de ses orientations premières. L'oralité est réversible: recevoir autrui en soi est se donner à lui. Plus encore: Freud et Winnicott soulignent la transition permanente et bouleversante de l'amour à la haine, de l'absorption au rejet. Dominique Bourdin peut à juste titre évoquer ici la mystique, où l'« amour oral » s'accomplit comme un amour « infiniment avide ", amour " impitoyable, vécu dans une réversibilité radicale et non pas dans une réciprocité ", amour de pure violence. Sans doute est-ce en cette analyse de l'oralité que Freud a le plus approché des conditions d'une spiritualité dévorante. Mais ce n'est là qu'une variante de l'oralité. L'avidité sans limites porte négation de l'autre : Saturne dévore ses enfants comme autant de séquences de temps qui s'engouffrent en cette «bouche d'ombre» qui vaut éternité. Mais si l'on peut dire que Margery Kempe, mystique anglaise au temps de l'hérésie lollarde, «dévore» le temps, c'est pour marquer qu'en elle le temps de l'histoire est mis en suspens au profit du temps christique, où tout autre temporalité s'abîme. L'avidité cède la place à l'incorporation, identification narcissique à cela - ici temps mythique - qui est consommé.

3 Du mythe, des figures en nombre sont convoquées. Ulysse et son parcours initiatique présenté par Pierre-Yves Brandt, scandé par des étapes où la séduction et la dévoration se répondent comme autant d'épreuves sur le chemin du retour vers son sol, qui est retour vers soi. Médée, mère infanticide, qui sacrifie ses enfants en offrande à sa généalogie solaire (Hubert Auque). Pygmalion, figure du prédateur en telle osmose avec sa proie qu'il rêve celle-ci consentante et jouissante de se faire désirer, et avaler (Sophie de Mijolla-Mellor). Avaler: à nouveau la bouche qui assure une fonction centrale dans l'univers onirique. En elle s'engloutissent des "morceaux d'altérité " comme il en va, selon Monique Schneider, du désir de combler un vide en soi qui fait trauma. Ici, absorption de l'autre en soi, avérant en miroir l'aspiration à être soi-même objet de désir. Là, dans l'offrande plénière de son corps à autrui, comme en ce symbole christique du pélican dévoré par sa progéniture, analysé par Myriam Vaucher, l'affirmation du lien cannibale comme " point originaire du lien à l'autre ». Il est clair, cependant, que si s'établit une relation de dévoration réciproque, si «l'un et l'autre s'avalent indéfiniment", jamais un sujet n'en naîtra, non plus qu'autrui en sa singularité. Aussi bien faut-il qu'à cette fusion diabolique, indifférenciée, d'où peut s'enclencher une relation "mélancolique ", soit mis un terme, et que séparation soit établie entre objet et sujet. Alors, écrit Philippe Jeammet, l'on peut devenir soi en « recevant les autres » en tant que tels : autres que soi.

4 Entre biologie et culture, l'oralité ; la bouche dévorante ; la dévoration de l'animal totémique, les troubles anorexiques, la manducation de la parole, dont l'ouvrage étonnamment ne traite pas, et qu'analysait Marcel Jousse dans son anthropologie de la mise en scène gestuelle dans le milieu ethnique palestinien, etc. En régime de chrétienté, l'Eucharistie : ceci est mon corps - ceci est mon sang. Thierry de Saussure invite à déployer plus largement l'argument d'oralité : de la Chute à la Cène. De la perte au Royaume. Du fruit défendu à l'offerte de chair et de sang. Du refus par Adam et Ève de "la limite constitutive de leur identité humaine", et du deuil qui s'ensuit de leur toute-puissance - à "l'intégration symbolique de la personne de Jésus» et la sanctification de son propre corps de communiant. Ainsi va, en religion, l'oralité : de la 
tentation sacrilège et létale, à l'absorption de la grâce et du salut. Sans doute ceci est-il affaire de foi : le credo précède la communion. Si bien que Bernard Pottier peut assurer que "Christ ne disparait pas quand on le "mange"; c'est nous qui disparaissons en lui ». Mais cet accomplissement ne se peut que sur les décombres d'une dévoration sauvage, et l'engendrement d'une oralité culturellement ritualisée. Jusqu'à ce que, rappelle Marcel Durrer, la parole rapportée par Marc, disant l'impureté comme venant du dedans de l'homme, inverse la relation de soi-même au monde. L'immonde est en soi, le monde est l'ailleurs, le monde est autrui. « Il n'est rien hors de l'humain qui en pénétrant en lui puisse le souiller ». Par le long détour du cannibalisme, sa violence, sa symbolique, l'humain est rapatrié en sa propre demeure. Et tout ce qui s'effectue de pulsion fantasmatique de dévoration peut s'entendre comme expulsion hors de soi de cet « étranger » qui habite en l'homme : lui-même. 